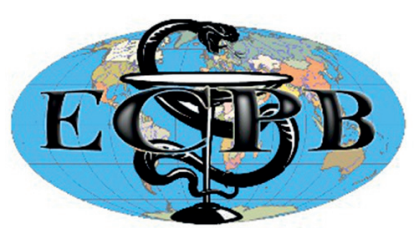

“ЕКСПЕРИМЕНТАЛЬНА ТА КЛІНІЧНА ФІЗІОЛОГІЯ І БІОХІМІЯ” "EXPERIMENTAL AND CLINICAL PHYSIOLOGY AND BIOCHEMISTRY" Науково-практичний журнал/Scientific-practical journal

Наукові статті / Research Articles

ECPB 2019, 3(87): 23-29. https://doi.org/

UDC 615.281:577.15:616.155.32

\title{
Effect of Fluoroquinolones on the Activity of the Glutathione System in the Peripheral Blood Lymphocytes
}

\author{
I.V. KOVALENKO, O.K. ONUFROVYCH, O.V. MELNYK, O.S. KORCHYNSKA, \\ N.M. VOROBETS, Z.D. VOROBETS ${ }^{1}$
}

Danylo Halytskyi Lviv National Medical University, Lviv, Ukraine

E-mail: Onufrovychok@gmail.com

An important role in the etiotropic therapy of purulent-inflammatory complications take fluoroquinolones which are active against pathogenic microflora. Due to their wide range of antimicrobial activity, low toxicity, good pharmacokinetics properties, they are widely use in the treatment of bacterial infections of different localization. These are drugs of ultra-wide range of activity, active against gram-positive and gram-negative, aerobic and anaerobic microorganisms, chlamydia, mycoplasma, mycobacteria [1-4]. Fluoroquinolones are synthesized by introducing into the molecule 4-quinolones - one, two or four fluorine atoms $[1,2]$.

These synthetic antibiotics have a specific mechanism of action, which is to inhibit the activity of DNA gyrase (topoisomerase II) and topoisomerase IV of bacterial cells - the enzyme responsible for the stability of the DNA structure of the bacteria and is involved in cell division [2,3,5]. Under the action of fluoroquinolones, the bacterial cell's DNA is despiralized, its spatial structure is disrupted and, as a consequence, the process of replication, transcription, translation, and cell death is impaired.

The pharmacodynamics of fluoroquinolones include antibacterial (bacteriocidal), postantibiotic and immunomodulatory effects [7,8]. Drugs 2 nd generations (for example, ciprofloxacin) are active in a wide range of gram-negative aerobic microorganisms as well as Staphylococcus aureus, salmonella, Escherichia coli [6]. Also active against mycobacterium tuberculosis. Moderately active in attitude to pneumococci, enterococci, chlamydia. Its bioavailability is $80 \%$.

Third-generation fluoroquinolones are highly active against pneumococci and intracellular pathogens, in particular mycoplasma and chlamydia [6]. Thus. levofloxacin has advantages over other fluoroquinolones against pneumococci, chlamydia, mycoplasma. More frequent it is used for the treatment of respiratory infections, as well as infections of the urogenital tract, skin.

New, IV generation fluoroquinolones, in particular moxifloxacin have considerably anymore activity against gram-positive microorganisms compared to previous generations of fluoroquinolones [6]. Moxifloxacin is most active against staphylococci, streptococci. In relation to pneumococci, it is in 4-16 times more active than ciprofloxacin. Moxifloxacin acts on polyresistant strains such as chlamydia, mycoplasma, ureaplasma in particular on mycobacterium of tuberculosis, which bioavailability is $90 \%$.

It is possible to assume that antibiotics of fluorchinolone if they enter human body also have influence on eukaryotic cells, in particular blood cells. It

(C) Kovalenko I.V., Onufrovych O.K., Melnyk O.V. et al., 2019 
is considered that lymphocytes of peripheral blood are the "metabolic mirror" of organism, and, consequently, can serve as a model for the study of influence of fluoroquinolones on the metabolic and regulatory systems of cells [9-11]. The purpose of this work was to study the effect of fluoroquinolones on lipid peroxidation and the activity of the glutathione antioxidant blood lymphocyte system.

Materials and methods. The object of research was the blood of practically healthy women. The total number of practically (clinically) healthy women, representative of the age (mean age 53.8-5.4 years) was 44. This group was formed from volunteers from among the employees of Danylo Halytsky Lviv National Medical University. Commission of Bioethics of Danylo Halytsky Lviv National Medical University (protocol No. 8 of October 22, 2018), violations of moral and ethical norms during the performance of this work were not revealed. Before turning to study, all patients and healthy donors were aware of patient information leaflets and gave informed consent to participate in research. Terms of sample selection meet the requirements of the principles of Helsinki Declaration on protection of human rights, Convention of Europe Council on human rights and biomedicine and the provisions of laws of Ukraine.

Blood collection by venipuncture was carried out from the vein mediana cubiti in the morning hours under conditions of physiological rest, on a empty stomach, in a quantity of $20 \mathrm{ml}$ in test tubes stabilized with heparin (final dilution $1: 100$ ). Blood dissolved in a $1: 1$ with physiological solution, washed in a gradient of density of the ficoll triumbrast $(\lambda=1.08 \mathrm{~g} / \mathrm{cm} 3)$ and centrifuged for 20 minutes at $500 \mathrm{~g}$. The removed interphase rings of mononuclear cells were washed twice within 10 minutes with physiological solution (Boyum, 1968).

After the last centrifugation, a small amount of physiological solution was added to the precipitate, resuspended and using a trypan blue, the count of the number of live and dead cells in the Goryaev camera was performed. The integrity and viability of blood lymphocytes in all experiments was not less than $95 \%$.

For permeabilization of blood lymphocyte membranes and disclosure of latent enzymatic activity, a saponin was added to the suspension of blood lymphocyte. This technique is based on previous works on lymphocytes. Blood lymphocytes were incubated for 10 minutes at moderate shaking in a solution containing saponin at a concentration of $0.2 \%$ (optimal concentration) [12].

Oxidative stress was evaluated by the measurement of the thiobarbituric acid reactive substance (TBARS). The TBARS reaction evaluates the levels of malondialdehyde, a product of lipid peroxidation [13]. Glutathione peroxidase (GP) activity was determined by the oxidation glutathione [14]. Glutathione reductase (GR) activity was assayed by measuring the oxidation NADPH [14]. Glutathine S-transpherase (GsT) activity was determined by the rate of conjugate by reaction with 1-chloro-2,4 dinitrobenzene as described [14]. The content of total glutathione was determined after completed reduction of glutathione through the use of glutathione reductase by means of Ellman's reagent [15]. The level of 5-trinitrobenzoic acid was monitored with a spectrophotometer at $412 \mathrm{~nm}$. To determine the content of oxidized glutathione (GSSH), 2-vinylpyridine was added to the incubation mixture to a final concentration of $2 \% 60$ min before the determination. The content of reduced glutathione (GSH) was calculated as the difference of contents between total glutathione and its oxidized form. The protein content of the lymphocyte mixture was determined by a modified Lowry method.

Experimental data were processed by methods of variation statistics using software MS Office. Differences were calculated using the t-Student test for independent groups, assuming $\mathrm{p} \leq 0.05$ as the minimum significance level. The results are presented as the mean \pm standard deviation of the mean.

Results and discussion. According to modern ideas the impact on the body of xenobiotics, drugs, the development of pathological processes are accompanied by violation of the mechanisms of antioxidant protection of cells $[13,14,16]$. The 
chemicals often initiate free radical processes in phospholipids of cell membranes that comprising polyunsaturated fatty acids are often initiated.

Intensification of lipid peroxidation leads to the accumulation of toxic products, which leads to a decrease in body resistance [10,13]. At the same time, the buffering capacity of the antioxidant system is quite large and is provided by various components.

An important place among AOS of the cell is the glutathione system, the components of which are involved in both enzymatic (glutathione peroxidase, glutathione reductase, glutathione transferase) and non-enzymatic (glutathione) reactions of AOS $[13,16]$. Although the glutathione system has been the subject of many researches, there is no consensus in the literature on its role in the body's response to the action of certain antibiotics or the development of pathological conditions. In this regard, the analysis of the functional state of the glutathione system under the action of antibiotics of fluoroquinolone series will reveal its role in the mechanism of action of these drugs.

We carried out a comparative study of the processes of lypoperoxidation and glutathione system in peripheral blood lymphocytes under the influence of fluoroquinolones of II-IV generations (Fig. 1). In all cases, the activation of LPO processes was shown, by determining the concentration of malondialdehyde, which is a secondary product of lipid peroxidation. Thus, in the blood lymphocytes of the control group, the concentration of MDA is $(4.1 \pm 0.4) \mu \mathrm{mol} / \mathrm{l}$. Under the action of ciprofloxacin (II generation), the processes of LPO was intensified in to 1.7 times relative to the parameters in the control group, where the MDA concentration reaching $(6.6 \pm 0.5) \mu \mathrm{mol} / \mathrm{l}(\mathrm{p}<0.001)$.

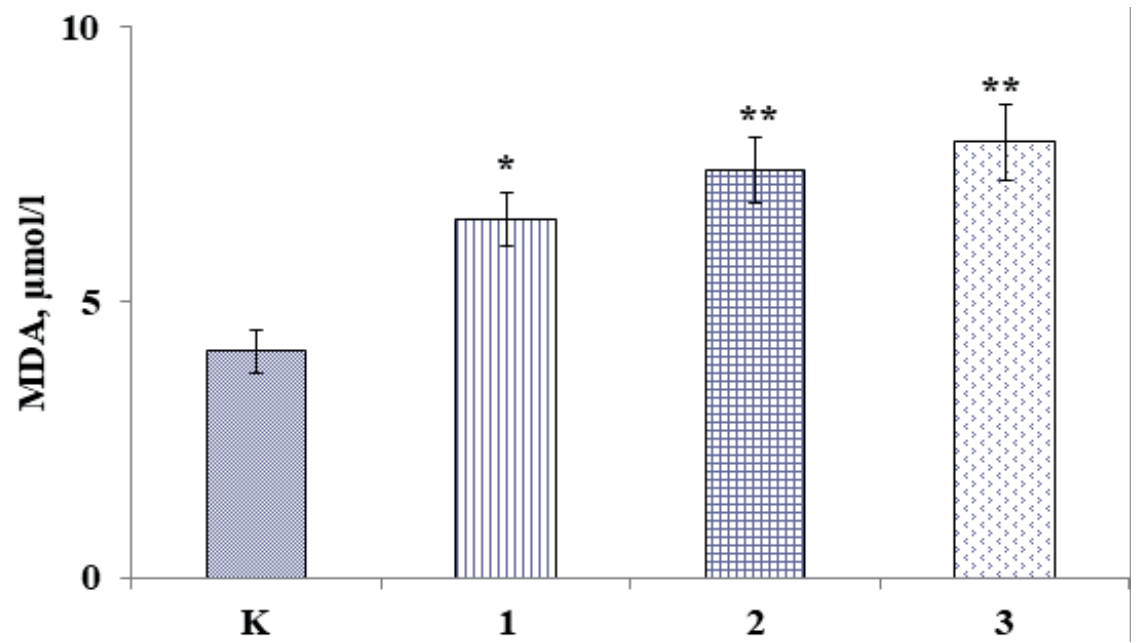

Fig. 1. Concentration of malondialdehyde in the blood lymphocytes of almost healthy women (control) and when exposed by fluoroquinolones - ciprofloxacin (1), levofloxacin (2) and moxifloxacin (3). $\mathrm{M} \pm \mathrm{m}, \mathrm{n}=8-12$.

Note: changes are probable for the lymphocyte values of control subjects, ${ }^{*} \mathrm{p}<0.001$

When the cells are exposed by levofloxacin (third generation), the processes of LPO is more activated, MDA concentration increases to $7,4 \pm 0,6) \mathrm{mmol} / \mathrm{l}$, that is in 1.8 times more then in control groop. A similar situation is observed when determining the concentration of MDA in blood lymphocytes under the action of moxifloxacin (IV generation). Moxifloxacin increases MDA to $7.9 \pm$ $0.7 \mu \mathrm{mol} / \mathrm{l}(\mathrm{p}<0.001)$. that is in 1.9 -times more than in the control groop. The direct dependence of the activation of the processes of LPO of the generations of antibiotics like moxifloxacin > levofloxacin $>$ ciprofloxacin can be observed. Thus, under the action of fluoroquinolones, the processes of LPO in blood lymphocytes are significantly intensified in $1.7-1.9$ times $(p<0.001)$. Along with 
the intensification of the processes of LPO, the corresponding changes in the activity of enzymes of the glutathione system have been revealed. Thus, it is shown that in the control the concentration of reduced glutathione in blood lymphocytes is $18.1 \pm 1.7 \mathrm{nmol} / \mathrm{mg}$ protein. When act on lymphocytes separately ciprofloxacin, levofloxacin or moxifloxacin, no significant changes in the concentration of glutathione were found, it fluctuated within $(17.9 \pm 1.6)-(18.2$ $\pm 1.7) \mathrm{nmol} / \mathrm{mg}$ protein $(\mathrm{p}>0.05)$.

However, the activity of glutathione peroxidase of lymphocytes under the action of ciprofloxacin increased from $154.2 \pm 13.4 \mathrm{nmol} \mathrm{GSH} / \mathrm{min} \cdot \mathrm{mg}$ protein (control) to $177.3 \pm 13.7$ ( $\mathrm{p}>0.05$ ), when exposed by levofloxacin - to $190.3 \pm$ 10.7 ( $\mathrm{p}<0.05)$, and when exposed by moxifloxacin - up to $199.3 \pm 14.7 \mathrm{nmol}$ GSH / min $\cdot \mathrm{mg}$ protein $(\mathrm{p}<0.05)$ (Fig. 2). A significant increasement of the activity of glutathione peroxidase occurs only under the action of moxifloxacin, 1.3 times.

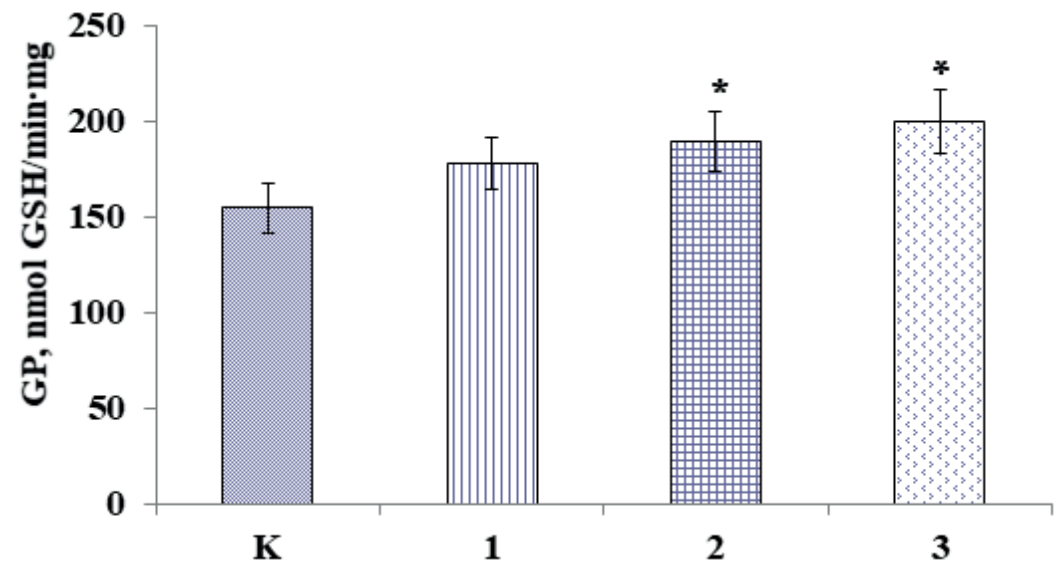

Fig. 2. The glutathione peroxidase activity in blood lymphocytes of practically healthy women

$(\mathrm{K}$ - control) and under the action of fluoroquinolones - ciprofloxacin (1), levofloxacin (2), moxifloxacin (3). $\mathrm{M} \pm \mathrm{m}, \mathrm{n}=8-12$.

Note: changes are probable for the lymphocyte values of control subjects, ${ }^{*} p<0.05$

Regarding the activity of glutathione reductase, in lymphocytes of the control groop it was $51.7 \pm 4.2 \mathrm{nmol} \mathrm{NADPH} / \mathrm{min} \cdot \mathrm{mg}$ protein (Fig. 3).

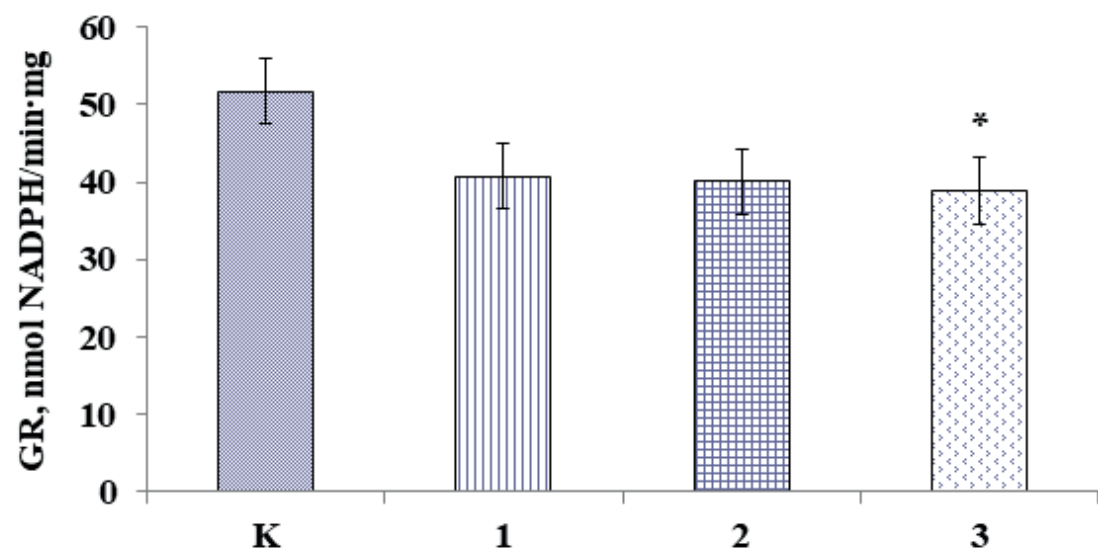

Fig. 3. The glutathione reductase activity in blood lymphocytes of practically healthy women

( $\mathrm{K}$ - control) and under the action of fluoroquinolones - ciprofloxacin (1), levofloxacin (2), moxifloxacin (3). $\mathrm{M} \pm \mathrm{m}, \mathrm{n}=8-12$.

Note: changes are probable for the lymphocyte values of control subjects, ${ }^{*} \mathrm{p}<0.001$ 
With ciprofloxacin, it decreased to $40.7 \pm 4.2(\mathrm{p}>0.05)$, levofloxacin - to $40.1 \pm 4.2(\mathrm{p}>0.05)$, and with moxifloxacin - to $37.9 \pm 3.1 \mathrm{nmol} \mathrm{NADPH} / \mathrm{min}$. $\mathrm{mg}$ protein $(\mathrm{p}<0.05)$.

Glutathione S-transferase activity in lymphocytes in control groop was 112.2 $\pm 9.2 \mathrm{nmol} \mathrm{GSH} / \mathrm{min} \cdot \mathrm{mg}$ protein (Fig. 4). Under the action of ciprofloxacin, it increased in $2.3(\mathrm{p}<0.001)$, levofloxacin in $3.1(\mathrm{p}<0.001)$, and moxifloxacin in 3.8 times $(p<0.001)$ relatively.

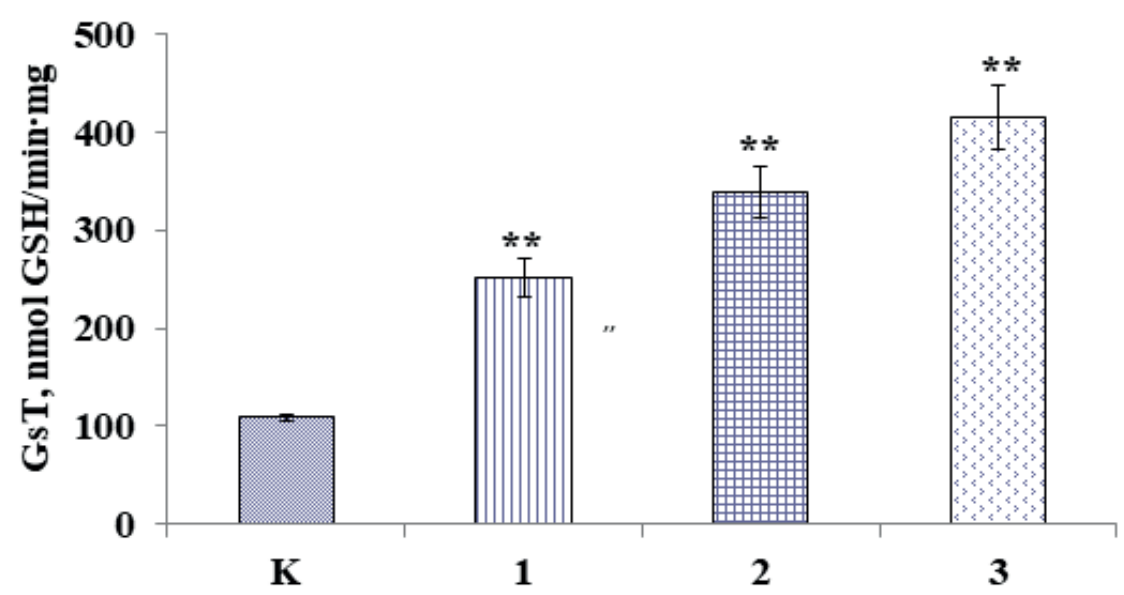

Fig. 4. The Glutathione S-transferase activity in blood lymphocytes

of practically healthy women ( $\mathrm{K}$ - control) and under the action of fluoroquinolones ciprofloxacin (1), levofloxacin (2) та moxifloxacin (3). $\mathrm{M} \pm \mathrm{m}, \mathrm{n}=8-12$.

Note: changes are probable for the lymphocyte values of control subjects, ${ }^{*} \mathrm{p}<0.001$

Thus, these antibiotics significantly activate the processes of LPO in lymphocytes and simultaneously activate the major enzymes of antioxidant protection - glutathione peroxidase and glutathione transferase. As for glutathione reductase activity, which reduce oxidized glutathione, its activity decreased. Activation of the enzymes of GP and GsT with the absence of endogenous synthesis of reduced glutathione can be explained due to the fact that the studies were performed in vitro at optimal substrate concentrations in incubation medium.

The obtained results are similar with some literature data showing that moxifloxacin in normal melanocytes leads to an increasement of the concentration of MDA and also activates glutathione peroxidase, superoxide dismutase and catalase [16]. Moxifloxacin has also been shown to increase the concentration of MDA in hepatocytes, but it also reduces the activity of catalase, superoxide dismutase and glutathione transferase [17]. On the other hand, the gatifloxacin fluoroquinolone has been shown leading to dose-dependently increasement of malonic dialdehyde concentration and a simultaneous decreasement of superoxide dismutase activity and glutathione levels in the blood, an increasement in catalase activity, glutathione peroxidase and glutathione transferase [18]. Other fluoroquinolone enrofloxacin did not cause oxidative stress in the blood, did not affect the activity of enzymes of the glutathione antioxidant system [9]. Thus, most studies demonstrate the activation of lipid peroxidation processes by fluoroquinolones and the activation of antioxidant system enzymes. However, there are likely to be some differences in the mechanisms of action of different fluoroquinolones and in the peculiarities of their response to different organs and tissues.

Conclusion. 1. Fluoroquinolones activate the processes of lipid peroxidation in blood lymphocytes.

2. Fluoroquinolones do not affect on the concentration of reduced glutathione in blood lymphocytes, but they increase the activity of glutathione peroxidase and glutathione transferase. 


\section{REFERENCES (ПОСИЛАННЯ)}

1. Almakaeva LG, Begunova NV, Naumenok LG, Dolya VG, Almakaev MS. Development of composition of infusion medication on basis of moxifloxacin. Annals of Mechnikov Institute. 2015;2:70-3 (in Ukrainian).

2. Dudikova ML, Vrynchanu NO, Dronova ML. New antibiotics of the quinolone series: prospects for use in medical practice. Pharmacology and Medical Toxicology. 2015;1(432), 3-12 (in Ukrainian).

3. Ferrandiz MJ, Martin-Galiano AJ, Arnanz C, Zimmerman T, de la Campa AG. Reactive oxygen species contribute to the bactericidal effects of the fluoroquinolone moxifloxacin in Streptococcus pneumonia. Antimicrobial Agents and Chemotherapy. 2016;60(1):409-17. doi: 10.1128/aac.02299-15.

4. Paliy GK, Nazarchuk OA, Nahajchuk VI, Osadchuk NI, Paliy DV, Kovalenko IV. Analytic prognostication of sensitivity of staphilococcus to fluoroquinolones. Svit Medicini i Biologii. 2015;3(51):103-6 (in Ukrainian).

5. Ambulkar PS, Ghosh SK, Indole IV, Pal AK. Genotoxic and cytotoxic effects of antibacterial drug, ciprofloxacin, on human lymphocytes in vitro. Nepal Medical College Journal. 2009;11(3): 147-51.

6. Kanyuka $O$, Paul O. Future use flioroquinolone generation in treatment bacterial infections. Nauk. Visnyk S. Gzhytskoho LNUVMBT. 2011;2(48): 107-11 (in Ukrainian).

7. Chatzika K, Manika K, Kontou P, Pitsiou G, Papakosta D, Zarogoulidis K, Kioumis I. Moxifloxacin pharmacokinetics and pleural fluid penetration in patients with pleural effusion. Antimicrobial Agents and Chemotherapy. 2014; 58(3):1315-9. DOI: 10.1128/AAC.02291-13.

8. Demchuk $H V$. Estimation of safety of fluoroquinolones for therapy of communityacquired pneumonia of the patients with diabetes mellitus. Visnyk Vinnytskoho Mededychnogo Univiversitetu. 2014;18(2):525-8 (in Ukrainian).

9. Coskun D, Parlak K, Dik B, Faki HE, Bahcivan E, Yazar E, Er A. Effect of enrofloxacin on the fluid/blood oxidative status and organ damage markers. Annual Research \& Review in Biology. 2018;25(3):1-7. doi: 10.9734/arrb/2018/40537.

10. Potjo, M., Cockeran, R., Theron, A.J., Feldman, C. \& Anderson, R. Effect of moxifloxacin on human neutrophil and T-lymphocyte functions in vitro. Pharmaceuticals. 2010; 3: 3570-80. DOI: $10.3390 / \mathrm{ph} 3123570$.

11. Riesbeck, $K$. Immunomodulating activity of quinolones: review. Journal of Chemotherapy. 2002;14(1):3-12. DOI: 10.1179/joc.2002.14.1.3.

12. Fafula RV, Iefremova UP, Luchkovska NE, Vorobets ZD, Kulachkovskii OR. Methodological approach to the study of the enzymatic spectrum of lymphocytes at pathological states using a detergent of saponin (ultrastructural study). Visnyk Problem Biologii i Medecini. 2012;1(96):163-6 (in Ukrainian).

13. Birben E, Sahiner MU, Sackesen C, Erzurum S, Kalayci O. Oxidative stress and antioxidant defense. World Allergy Organ J. 2012;5(1):9-19.

14. Gautam N, Das S, Mahapatra SK, Chakraborty SP, Kundu PK, Roy S. Age associated oxidative damage in lymphocytes. Oxid. Med. Cell Longev. 2010;3(4):275-82. doi: 10.4161/ oxim.3.4.12860.

15. Anderson ME. Determination of glutathione and glutathione disulfide in biological samples. Methods in Enzymology. 1985;113:548-55.

16. Beberok A, Wrzesniok D, Otreba M, Milinski M, Rok J, Buszman E. Effect of norfloxacin and mixifloxacin on melanin synthesis and antioxidant enzymes activity in normal human melanocytes. Mol. Cell. Biochem. 2015;401:107-14. doi: 10.1007/s11010-014-2297-7.

17. Ore A, Olayinka ET. Influence of moxifloxacin on hepatic redox status and plasma biomarkers of hepatotoxicity and nephrotoxicity in rat. Biochemistry Research International. 2015;15:1-8. doi: 10.1155/2015/192724.

18. Kumbhar GB, Khan AM, Rampal S. Evaluation of gatifloxacin for its potential to induce antioxidant imbalance and retinopathy in rabbits. Human \& Experimental Toxicology. 2014;34(4):372-9. doi: 10.1177/0960327114530743. 
RESEARCH ARTICLE

\title{
Effect of Fluoroquinolones on the Activity of the Glutathione System in the Peripheral Blood Lymphocytes
}

\author{
I.V. KOVALENKO, O.K. ONUFROVYCH, O.V. MELNYK, O.S. KORCHYNSKA, \\ N.M. VOROBETS, Z.D. VOROBETS \\ Danylo Halytskyi Lviv National Medical University, Lviv, Ukraine
}

\section{E-mail: Onufrovychok@gmail.com}

An important role in the etiotropic therapy of purulent-inflammatory complications take fluoroquinolones which are active against pathogenic microflora. Due to their wide range of antimicrobial activity, low toxicity, good pharmacokinetics properties, they are widely using in the treatment of bacterial infections of different localization. These are drugs of ultra-wide range of activity, active against gram-positive and gram-negative, aerobic and anaerobic microorganisms, chlamydia, mycoplasma, mycobacteria.

It is possible to assume that a number of antibiotics fluoroquinolone if it enters in a human body also act on eukaryotic cells, in particular blood cells. It is considered that lymphocytes of peripheral blood are the "metabolic mirror" of organism, and, consequently, can serve as a model for the study of influence of fluoroquinolones on the metabolic and regulatory systems of cells. The purpose of this work was a study the effect of a number of fluoroquinolones on lipid peroxidation and the activity of the glutathione antioxidant blood lymphocyte system. The object of research was the blood of practically healthy women.

We carried out a comparative study of the processes of lypoperoxidation and glutathione system in peripheral blood lymphocytes under the influence of fluoroquinolones of II - IV generations. In all cases, the activation of LPO processes is shown, by determining the concentration of malondialdehyde, which is a secondary product of lipid peroxidation. Thus, in the blood lymphocytes of the control group, the concentration of MDA is $(4.1 \pm 0.4) \mu \mathrm{mol} / \mathrm{l}$. With the action of ciprofloxacin (II generation), the processes of GHI are intensified 1.7 times relative to the parameters in the control group, with the MDA concentration reaching $(6.6 \pm 0.5) \mu \mathrm{mol} / \mathrm{l}(\mathrm{p}$ $<0.001$ ). When exposed to cells levofloxacin (third generation) processes more activated LPO, MDA concentration increases to $7,4 \pm 0,6) \mathrm{mmol} / \mathrm{L}$, that is about 1.8 times to control values. A similar situation is observed when determining the concentration of MDA in blood lymphocytes under the action of moxifloxacin (IV generation). Moxifloxacin resulted in a 1.9-fold increase in MDA to $7.9 \pm 0.7 \mu \mathrm{mol} / \mathrm{l}(\mathrm{p}<0.001)$.

The activity of glutathione peroxidase lymphocytes under the action of ciprofloxacin increased from $154.2 \pm 13.4 \mathrm{nmol} \mathrm{GSH} / \mathrm{min} \cdot \mathrm{mg}$ protein (control) to $177.3 \pm 13.7$ ( $\mathrm{p}>0.05$ ), when exposed to levofloxacin - to $190.3 \pm 10.7$ ( $\mathrm{p}<0.05)$, and when exposed to moxifloxacin - up to $199.3 \pm$ $14.7 \mathrm{nmol} \mathrm{GSH} / \mathrm{min} \cdot \mathrm{mg}$ protein $(\mathrm{p}<0.05)$. That is, a significant increase in the activity of glutathione peroxidase occurs only under the action of moxifloxacin, 1.3 times.

Regarding the activity of glutathione reductase, in lymphocytes in control it was $51.7 \pm$ $4.2 \mathrm{nmol} \mathrm{NADPH} / \mathrm{min} \cdot \mathrm{mg}$ protein. With ciprofloxacin, it decreased to $40.7 \pm 4.2(\mathrm{p}>0.05)$, levofloxacin - to $40.1 \pm 4.2$ ( $>0.05)$, and with moxifloxacin - to $37.9 \pm 3.1 \mathrm{nmol} \mathrm{NADPH} / \mathrm{min}$ - mg protein.

Glutathione S-transferase activity in lymphocytes in control was $112.2 \pm 9.2 \mathrm{nmol} \mathrm{GSH} / \mathrm{min}$ - mg protein. With ciprofloxacin, it increased 2.3 ( $p<0.001)$, levofloxacin $3.1(p<0.001)$, and moxifloxacin 3.8 times $(\mathrm{p}<0.001)$.

We presume that fluoroquinolones activate the processes of lipid peroxidation in blood lymphocytes. Fluoroquinolones do not affect the concentration of reduced glutathione in blood lymphocytes, but they do increase the activity of glutathione peroxidase and glutathione S-transferase.

Key words: fluoroquinolones, lymphocytes, lipid peroxidation, glutathione peroxidase, glutathione reductase, glutathione $\mathrm{S}$-transferase. 